doi:10.1016/j.prevetmed.2006.04.014

Copyright (c) 2006 Elsevier B.V. All rights reserved.

\title{
Spatial spreading of Echinococcus multilocularis in Red foxes (Vulpes vulpes) across nation borders in Western Europe
}

\section{Muriel Vervaeke ${ }^{a} *$, Joke van der Giessen ${ }^{b}$, Bernard Brochier ${ }^{c}$, Bernard Losson $^{d}$, Kurt Jordaens ${ }^{a}$, Ron Verhagen ${ }^{a}$, Cor de Lezenne Coulander ${ }^{b}$ and Peter Teunis ${ }^{b}$}

\author{
anniversity of Antwerp, Department of Biology, Groenenborgerlaan 171, B-2020 \\ Antwerpen, Belgium \\ ${ }^{\mathrm{b}}$ National Institute for Public Health and the Environment, Antonie van \\ Leeuwenhoeklaan 9, P.O. Box 1, 3720 BA Bilthoven, The Netherlands \\ 'Scientific Institute of Public Health, Rue Juliette Wytsman 14, B-1050 Brussel, \\ Belgium \\ dUniversité de Liège, Département de Parasitologie et Pathologie des Maladies \\ Parasitaires, Boulevard de Colonster 20, B-4000 Liège, Belgium \\ * Corresponding author. Tel.: +32 498 745574; fax: +32 32643474.
}

\begin{abstract}
The occurrence of the fox tapeworm Echinococcus multilocularis in Red foxes was studied in Belgium and a neighbouring region in The Netherlands. A total number of 1202 foxes were analysed (1018 in Belgium and 184 in The Netherlands) of which 179 were infected with E. multilocularis (164 in Belgium and 15 in The Netherlands). Further, the spatial distribution of infection among sampled foxes was analysed with an ellipsoidal gradient, demonstrating a decreasing prevalence in northwestern direction. Using this gradient, we showed that the spatial patterns of infection in Belgium and the neighbouring region in The Netherlands correspond, indicating a continuous distribution of E. multilocularis across the nation borders. Part of the Belgian data allowed investigating temporal changes in the spatial distribution of $E$. multilocularis. This revealed a northwestern spread of E. multilocularis.
\end{abstract}

\section{Introduction}

Echinococcus multilocularis is a small tapeworm belonging to the family of the Taeniidae. In Europe, the life cycle of $E$. multilocularis is predominantly sylvatic, i.e. involving wild carnivores (mainly foxes of the genera Vulpes and Alopex) as final hosts and several species of small mammals (mainly rodents of the families Arvicolidae and Cricetidae) as intermediate hosts (Rausch, 1995 and Eckert et al., 2001). Adult worms live in the small intestines of the final host and their eggs are shed with the faeces. Intermediate hosts are infected when they ingest eggs which then develop into larvae (i.e. metacestode stage with protoscolices) that form cysts in internal organs, mainly the liver. Infected intermediate hosts are consumed by final hosts in which the adult worm stage of the parasite develops. Domestic dogs (Canis lupus $f$. familiaris) and cats (Felis sylvestris $f$. catus) may create a synanthropic cycle when they ingest rodents harbouring the metacestode stage with protoscolices. The sylvatic cycle of E. multilocularis is of epidemiological interest since it is the source of infection for humans, which may become infected after ingesting infective eggs and for domestic carnivores (i.e. 
dogs and cats) which become infected after consuming intermediate hosts infected with fertile metacestodes. Once established, the synanthropic cycle can also serve as a source of infection for intermediate hosts and aberrant hosts (such as humans).

E. multilocularis is widely distributed in the northern hemisphere where it is endemic in several west and central European regions, most of northern and central Eurasia and parts of North America (Eckert et al., 2001). In the previous decade, a lot of new data have been published on prevalences of E. multilocularis in final and intermediate hosts in areas where it had previously not been recorded. At present, the known geographic range of the parasite in west and central Europe includes regions in Austria, Switzerland, France, Germany, Liechtenstein, Luxemburg, Belgium, The Netherlands, Poland, Czech Republic, Slovak Republic, Denmark and the Norwegian Islands of Svalbard (Brochier et al., 1992, Lucius and Bilger, 1995, Schantz et al., 1995, Kolarova et al., 1996, Eskens, 1997, Losson et al., 1997, Tackmann et al., 1998, Dubinsky et al., 1999, Kolarova, 1999, Romig et al., 1999, van der Giessen et al., 1999, Eckert et al., 2000, Eckert et al., 2001, Balicka-Ramisz et al., 2003 and Vervaeke et al., 2003). Comparison of existing prevalence data from animal hosts in different European regions is difficult because of differences in sample sizes and detection methods (Vervaeke et al., 2005). Moreover, only a few areas are monitored for longer periods of time. Hence, currently it remains unknown whether E. multilocularis has extended its range recently or whether the parasite has simply remained undetected until now. However, a trend towards increased parasite density and range is apparent for central and parts of west Europe (Romig, 2002 and Sréter et al., 2003).

Human infection with the larval form of E. multilocularis is considered as one of the most pathogenic autochthonous parasitic zoonoses in central Europe and is usually lethal if left untreated (Ammann and Eckert, 1995, Eckert et al., 2001 and Kern et al., 2003). So far, the occurrence of human alveolar echinococcosis (AE) in Europe is characterised by a low but persistent incidence, with an estimated annual incidence of $0.02-1.4$ cases per 100,000 inhabitants for the endemic regions of central Europe (Eckert and Deplazes, 1999). Data from EurEchinoReg (Surveillance for human AE in Europe, 1982-2000) shows 559 AE patients in Europe combined with the occurrence of human cases outside endemic regions (Kern et al., 2003). Moreover, increasing fox populations in most European countries over the last decades (Artois, 1997, Romig et al., 1999 and Vervaeke et al., 2003) and their invasion of urban and suburban settings (Hofer et al., 2000, Deplazes and Eckert, 2001, Giraudoux et al., 2001, Gloor et al., 2001 and Deplazes et al., 2004) increased awareness of scientists and authorities of the potential public health risk of this zoonotic tapeworm.

The aims of this paper were (i) to analyse the spatial distribution of $E$. multilocularis in foxes in Belgium and a neighbouring area in the south of The Netherlands to obtain quantitative insight into the potential spread of the parasite and (ii) to examine the temporal variation in the prevalence of $E$. multilocularis. Spatial analysis may provide useful insights into the heterogeneity in the distribution pattern of $E$. multilocularis and its migration. In order to spot largescale geographical patterns in distribution, international monitoring of $E$. multilocularis in wildlife requires the analysis of prevalence data across borders. As the studied region is situated at the margin of the endemic region of $E$. multilocularis in Western Europe, our primary interest was to find out where the prevalence is highest and how it changes if one moves away from this endemic focus. For this purpose, we have concentrated on finding a spatial gradient of $E$. multilocularis prevalence in foxes, to locate prevalence contours and to find 
directions of steepest descent in prevalence. To our knowledge this paper presents the first spatial analysis of parasite infection across border regions. For southern Belgium, a series of annual samples of spatial occurrence data were used to describe temporal changes in spatial distribution of E. multilocularis over the period 1998-2002.

\section{Methodology}

Two separate data sets on intestinal infections of Red foxes with E. multilocularis were collected. A first data set comprised a total of 1018 foxes that were randomly sampled in different regions in Belgium over the period 1996-2002 (Brochier et al., 1992, Losson et al., 1997, Losson et al., 2003 and Vervaeke et al., 2003). A second data set comprised 196 foxes that were collected during the period 2002-2003 in the province of Limburg in the southern part of The Netherlands (van der Giessen et al., 2004a and van der Giessen et al., 2004b). This province is situated adjacent to the border with Belgium. Foxes were collected as road victims or as hunting casualties. The geographical co-ordinates of the positions where foxes were shot or found as road victim were noted. All surveys used the intestinal scraping technique to detect $E$. multilocularis (see Delplazes and Eckert, 1996 and Eckert et al., 2001). The small intestine was placed on a plastic sheet, divided in five equal parts and each part was opened in full length with scissors. After removal of coarse material (stones and bones) and large parasites, deep mucosal scrapings were made using microscopic slides. The mucosal material adhering to the slide was transferred to a plastic petri dish and squashed to a thin layer by means of pressure on the slide. A mucosal scraping was taken at the proximal, middle and posterior third of each of the five parts of the small intestine and these mucosal squashes were then examined under a stereoscopic microscope for the presence of adult E. multilocularis tapeworms.

The geographical positions of all foxes were recorded in standard co-ordinates, allowing a logistic regression with the position vector $\vec{x}=(x, y)$ as covariable:

$$
\log \left(\frac{p}{1-p}\right)=f(x, y)
$$

A linear model for the probability that a captured fox was infected with $E$. multilocularis can be written as $f(x, y)=a_{1} x+a_{2} y+b$ so that contours are linear with direction $a_{2} / a_{1}$ and offset $b$.

The probability that a captured fox was infected with E. multilocularis was described as a function $f(x, y)$ describing the spatial variation according an ellipsoidal gradient model:

$$
f(x, y)=a\left(x-x_{0}\right)^{2}+a b\left(y-y_{0}\right)^{2}+c
$$

so that contours are ellipsoidal with origin $\left(x_{0}\right.$ and $\left.y_{0}\right)$, scale parameter $a$ and eccentricity parameter $b$ and main axes: Fig. 1 .

$$
\left(\frac{1}{\sqrt{|a|}}, \frac{1}{\sqrt{|a b|}}\right)
$$




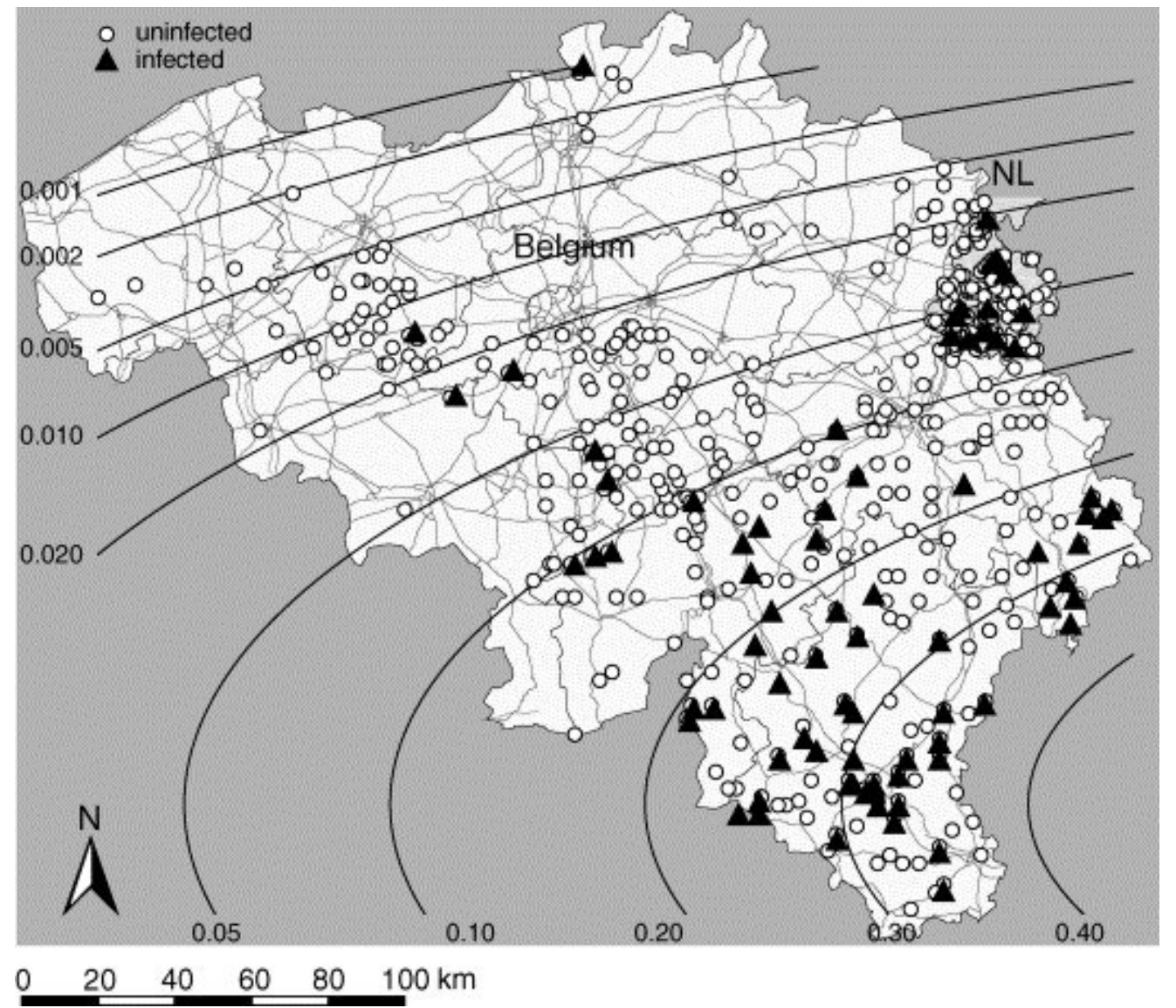

Fig. 1. Prevalence contours $(\times 100 \%)$ of Echinococcus multilocularis in foxes from Belgium and the province of Limburg in The Netherlands estimated using a logistic regression. Symbols indicate the geographic position of uninfected (black) and infected (red) foxes (crosses: Belgium; dots: The Netherlands).

The third parameter $c$ is an offset term which can be used to offset overall prevalence levels; an increase in $c$ increases the prevalence everywhere in the graph. The scale parameter a determines the magnitude of the ellipsoidal contours. A special case is when $a=0$ which means that the prevalence is constant with $p=\exp (c) /[1+\exp (c)]$. The eccentricity parameter $b$ determines how much the contour deviates from a circle; when $b=1$ the contour is perfectly circular, for very large $b$ or very small $b$ the contour approaches a straight line. For negative values of $b$ the contours assume a hyperbolical shape. For example, when $a=0$ and $c=-1.74$, then $f(x, y)=-1.74$ and

$p=\exp (-1.74) /[1+\exp (-1.74)]=0.176 / 1.176=0.149$ or $14.9 \%$. Maximum likelihood values were obtained for the parameters $(a-c)$ using numerical optimization routines in Mathematica $($ ) (Wolfram Research, 2004, Mathematica Version 5.1, http://www.wolfram.com). In order to assess parameter uncertainty, an adaptive rejection algorithm (Metropolis-Hastings) was used to sample from the likelihood function and to obtain Monte Carlo samples of parameter values (Gilks et al., 1996). These were then used to calculate confidence intervals of the gradient surface (Fig. 2) (Carlin and Louis, 1996 and Gilks et al., 1996). The optimum -2 log-likelihood value for the fitted gradient model was tested against a uniform prevalence $(a=0)$ in a likelihood ratio test. 


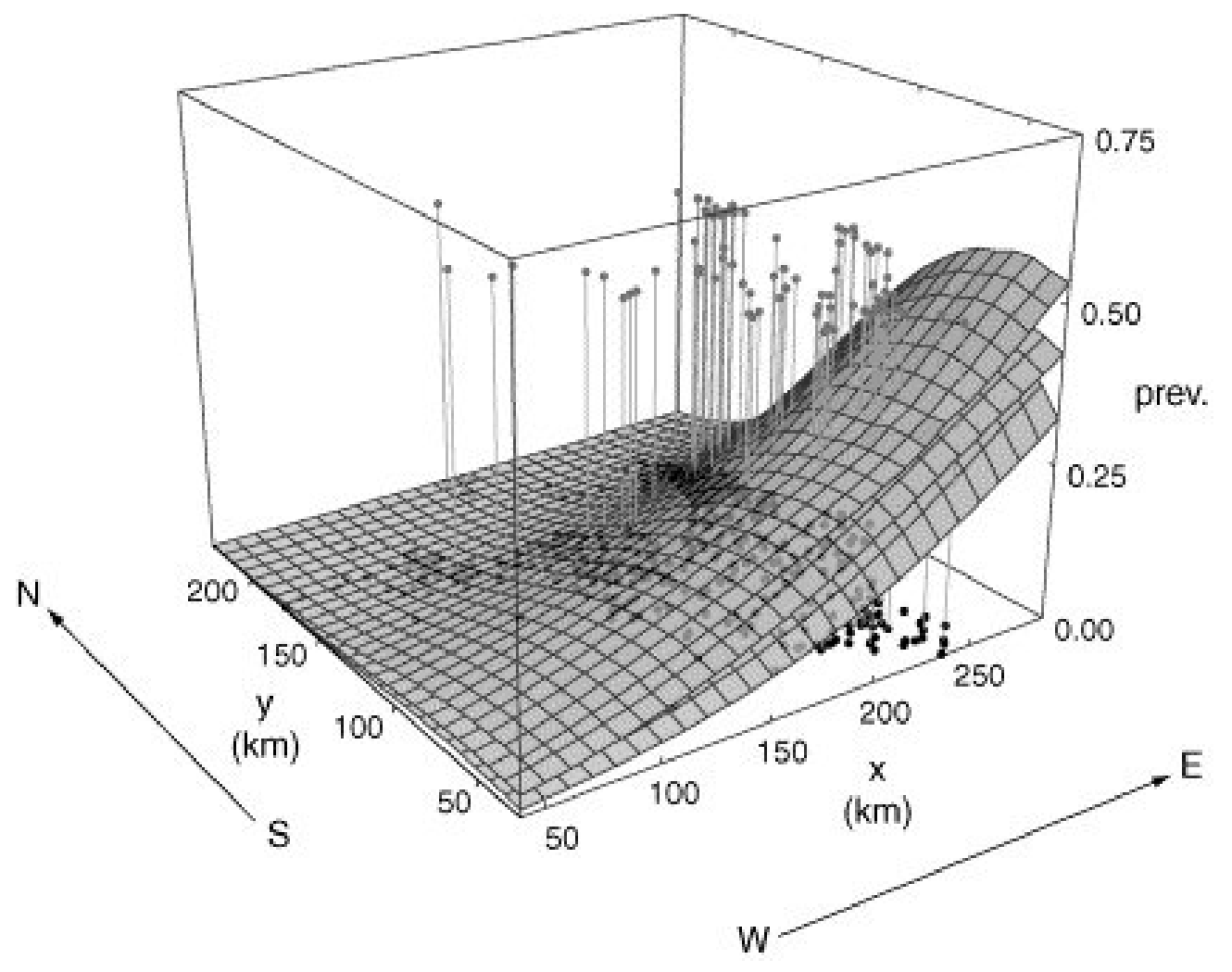

Fig. 2. Three-dimensional prevalence surface with upper (0.975) and lower (0.025) confidence limits of Echinococcus multilocularis in foxes from Belgium and the province of Limburg in The Netherlands. The geographic positions of uninfected foxes are presented as black dots in the ground plane; infected foxes are presented as elevated dots. [(prev. $) \times 100 \%=$ prevalence]. Distances $(y$ : north-south and $x$ : east-west) in kilometres.

The data from southern Belgium, collected in successive years (i.e. 1998, 1999, 2000, 2001 and 2002), with samples of roughly comparable sizes (i.e. 228, 128, 133,187 and 142 foxes) and with locations of examined foxes more or less evenly spread across the same region, were used to examine temporal changes in the prevalence gradient. To this end, we fitted the model to the series of yearly observations, using single values of the parameters $b$ and $c$ and $\left(x_{0}\right.$ and $\left.y_{0}\right)$ and a separate value of the contour scale parameter $a$ for each year. Because of possible temporal inconsistencies that might affect the results (i.e. the data from the province of Limburg in The Netherlands were collected after those from Belgium), this analysis was restricted to the Belgian data.

\section{Results}

\subsection{Spatial analyses of the distribution of E. multilocularis in Belgium and The Netherlands}

Results of the detection of E. multilocularis in several studies are shown in Table 1. In Limburg (The Netherlands) 184 foxes out of a total of 196 were tested with the intestinal scraping method in 2002-2003 and 15 foxes were found to be positive for E. multilocularis. In the northern part of Belgium 200 foxes were collected in 1996-1999 with four positive for E. multilocularis. Data from the southern part of Belgium were collected yearly from 1998 to 2002, with 
successive sample sizes of $228,128,133,187$ and 142 animals, with 54, 29, 37, 16 and 24 infected foxes, respectively.

Table 1.

Occurrence of Echinococcus multilocularis in Red foxes in Belgium and the province of Limburg in The Netherlands

\begin{tabular}{|c|c|c|c|c|c|c|}
\hline \multirow[t]{2}{*}{ Region } & \multicolumn{6}{|l|}{ Foxes } \\
\hline & Period & Total & Negative & Positive & Prevalence & C.I. $(95 \%)$ \\
\hline Northern Belgium & 1996-1999 & 200 & 196 & 4 & 2.0 & $0.7-5.1$ \\
\hline Southern Belgium & 1998 & 228 & 174 & 54 & 23.7 & $18.1-29.2$ \\
\hline Southern Belgium & 1999 & 128 & 99 & 29 & 22.7 & $15.7-29.3$ \\
\hline Southern Belgium & 2000 & 133 & 96 & 37 & 27.8 & $20.9-37.3$ \\
\hline Southern Belgium & 2001 & 187 & 171 & 16 & 8.6 & $4.5-13.9$ \\
\hline Southern Belgium & 2002 & 142 & 118 & 24 & 16.9 & $11.1-24.1$ \\
\hline Southern Limburg & $2002-2003$ & 184 & 169 & 15 & 8.2 & $4.9-12.7$ \\
\hline
\end{tabular}

Total number of investigated, positive and negative foxes and estimated prevalences (with 95\% confidence interval), per region and sampling period are given.

Table 2 shows maximum likelihood estimates for the parameters of the gradient model and corresponding values of -2 log-likelihood. The optimum -2 loglikelihood value for the fitted gradient model was tested against a uniform prevalence $(a=0)$ and was highly significant (deviance $=138.1$;

d.f. $=5-1=4 ; p<0.0001$ ). Interestingly, adding the data from a separate survey in the province of Limburg in The Netherlands, adjacent to the northeastern border of Belgium, appeared to only solidify the conclusion that there is a decreasing E. multilocularis prevalence in northwestern direction (Fig. 1). A likelihood ratio test using each study separately and both studies joined showed agreement. Indeed, the separate -2 log-likelihood values for the Dutch and Belgian studies were 101.5 and 763.5, respectively and the -2 log-likelihood value was 873.6 for the pooled data. This yields a deviance of 8.58 (i.e. $873.58-(101.48+763.52)$ with d.f. $=6$ and $p=0.87$ and hence, all surveys fitted the same spatial gradient (Table 2 ). The deviance between linear and ellipsoidal gradient models fitted to the combined Belgian and Dutch data was 7.98, with d.f. $=2, p=0.98$. Hence, the ellipsoidal gradient model performs significantly better than a linear gradient model. 
Table 2.

Prevalence gradients for Echinococcus multilocularis in Red foxes for 1998-2002: Model comparison

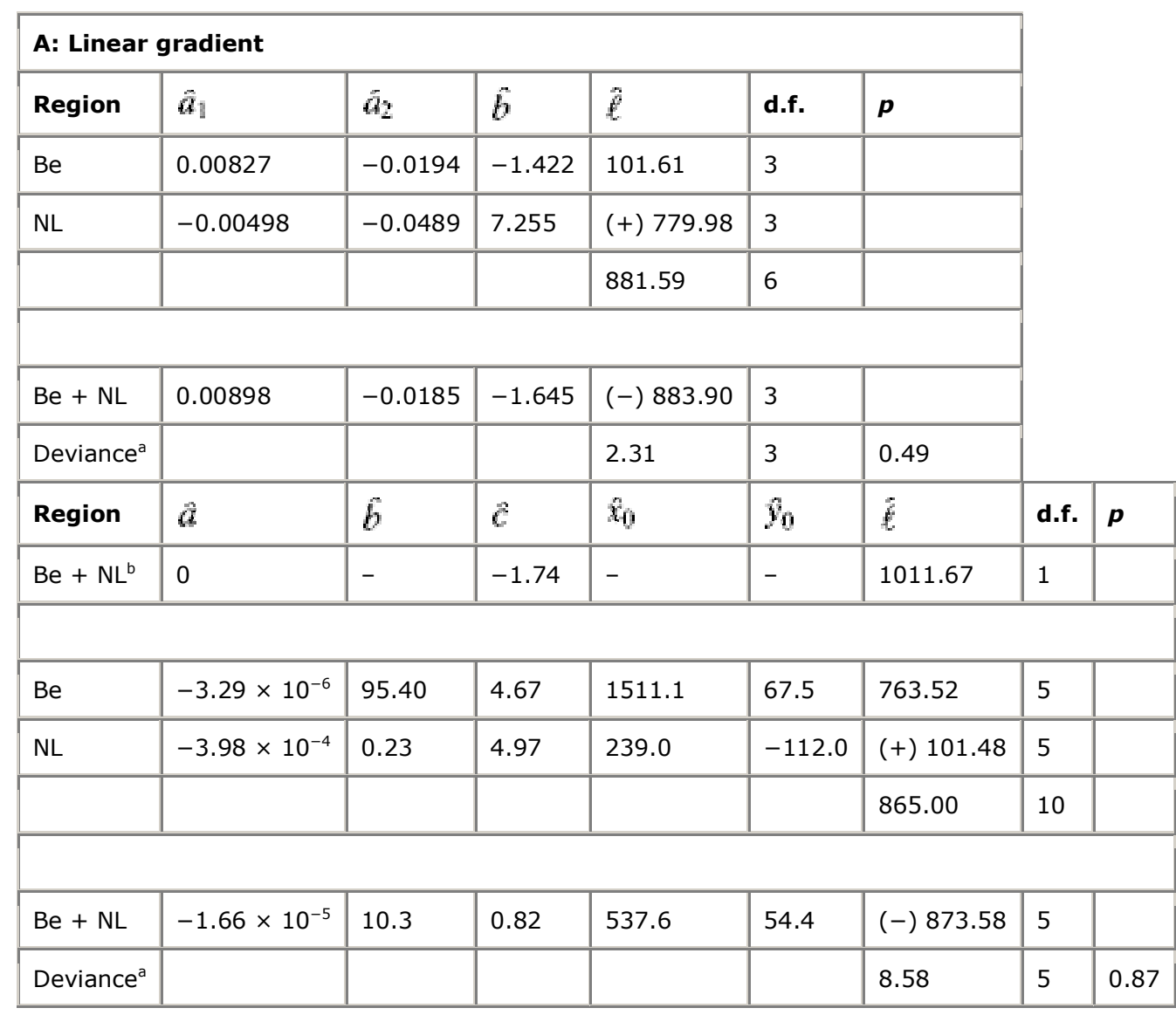

( $-2 \log$ ) Maximum likelihood values for the linear $(A)$ and ellipsoidal (B) gradient model fitted to the Belgian (Be) and Dutch (NL) data. Deviance between linear and ellipsoidal gradient $=7.98$, d.f. $=2, p=0.98$. Hence, the ellipsoidal gradient model performs significantly better than a linear gradient model.

${ }^{\text {a }}$ Separate gradients for each region $(\mathrm{Be} ; \mathrm{NL}$ ) and single joint gradient (Be $+\mathrm{NL}$ ) compared in likelihood ratio test: in both cases no significant difference $(p<0.95)$.

${ }^{b}$ Constant prevalence model $(a=0): \hat{c}=-1.74$, corresponding to an overall prevalence estimate of $14.9 \%$.

The maximum likelihood gradient for the joint Belgian and Dutch observations, superimposed on a map of the region is given in Fig. 1. This figure shows that $E$. multilocularis positive foxes were detected more often in southern Belgium, near the border to France and Germany in comparison with northern Belgium. In The Netherlands, the sampling density was relatively high compared to Belgium, but the prevalence appears similar to the adjoining area in Belgium. Model analysis suggested that the prevalence in northern parts of Belgium near the Dutch border and northward is low, possibly $0.1 \%$ or less, while the epicentre of $E$.

multilocularis infection may be situated southeastward, i.e. in Germany (Fig. 1). The estimated prevalence in the southernmost part of Belgium (i.e. near the border with France and Germany) is approximately $40 \%$ and decreases to approximately $10 \%$ near the border with Limburg in The Netherlands. Fig. 2 
shows a three-dimensional graph of the same prevalence gradient, with a (95\%) confidence range to illustrate the strength of evidence for the existence of a SENW gradient in the prevalence of infected foxes.

\subsection{Temporal analysis of the spatial distribution of E. multilocularis in southern Belgium}

Table 3 shows the results of the temporal data analysis of southern Belgium. The overall prevalence of E. multilocularis in foxes is high (23-28\%) until 2000. In 2001 , there is a drop in prevalence, followed by a slight increase in 2002. A series of constant (i.e. spatially uniform) prevalences provided a poor description, whereas an ellipsoidal gradient with only the scale parameter different by year did not fit significantly worse than an unconstrained model leaving all five parameters (i.e. $a-c$ and $x_{0}$ and $y_{0}$ ) free for each year (see Table 3 for details). Fig. 3 shows successive contour graphs of the prevalence gradient of $E$. multilocularis in foxes, based on data from southern Belgium. The sizes of the contours in Fig. 3 indicate an increasing prevalence until 2000 (note, for instance, the shift of the 0.01 contour), whereas in 2001, the 0.01 contour decreased in size. In 2002, this 0.01 contour has increased again slightly. Note that only the scale parameter needs to be changed among graphs; location and eccentricity of the ellipsoidal gradients can be kept the same. The resulting series of gradients provided a strong improvement in goodness of fit compared to a single, stationary gradient fitted to the whole series, while the deviance from a model where all five parameters (i.e. $a-c$ and $x_{0}$ and $y_{0}$ ) were fitted separately for each year was not significantly better (deviance $=20.48$, d.f. $=16 ; p=0.80$ ). The series of gradients fitted to the successive years (1998-2002) for southern Belgium indicated a distinct increase in prevalence in the southermost part of the country from 1998 until 2000 accompanied by a spread of E. multilocularis in northwestern direction. In 2001, there appears to be a sharp decrease, whereas in 2002, we find a higher prevalence again, as seems obvious from the overall prevalences given in Table 1.

Table 3.

Prevalence gradients for Echinococcus multilocularis in Red foxes for 1998-2002: successive years

\begin{tabular}{|l|l|l|l|l|l|l|l|}
\hline & Year & $a$ & $\hat{b}$ & $\hat{c}$ & $\hat{x}_{0}$ & $\hat{y}_{0}$ & $\hat{\ell}$ \\
\hline Constant prevalence \\
\hline & 1998 & 0 & - & -1.17 & - & - & 249.62 \\
\hline & 1999 & 0 & - & -1.23 & - & - & 136.98 \\
\hline & 2000 & 0 & - & -0.95 & - & - & 157.27 \\
\hline & 2001 & 0 & - & -2.37 & - & - & 109.26 \\
\hline & 2002 & 0 & - & -1.59 & - & - & 129.03 \\
\hline
\end{tabular}




\begin{tabular}{|c|c|c|c|c|c|c|c|}
\hline & Year & $\hat{a}$ & $\hat{b}$ & $\hat{c}$ & $\hat{x}_{0}$ & $\hat{y}_{0}$ & $\hat{2}$ \\
\hline \multicolumn{8}{|c|}{ Full model } \\
\hline & 1998 & $-3.53 \times 10^{-6}$ & 118.91 & 17.06 & 2459.0 & 43.8 & 212.06 \\
\hline & 1999 & $-9.41 \times 10^{-6}$ & 11.32 & 5.81 & 1035.1 & 22.5 & 127.83 \\
\hline & 2000 & $-2.33 \times 10^{-4}$ & 0.79 & 0.40 & 234.0 & 44.5 & 137.74 \\
\hline & 2001 & $-2.60 \times 10^{-4}$ & 3.04 & -0.19 & 256.1 & 91.0 & 90.57 \\
\hline & 2002 & $-2.70 \times 10^{-3}$ & 0.20 & 0.10 & 219.9 & 84.6 & 104.42 \\
\hline Total & & & & & & & 672.61 \\
\hline \multicolumn{8}{|c|}{ Shared parmeters ${ }^{\mathrm{b}}$} \\
\hline & 1998 & $-2.39 \times 10^{-4}$ & 4.28 & -0.20 & 265.3 & 76.9 & - \\
\hline & 1999 & $-1.06 \times 10^{-4}$ & 4.28 & -0.20 & 265.3 & 76.9 & - \\
\hline & 2000 & $-8.82 \times 10^{-5}$ & 4.28 & -0.20 & 265.3 & 76.9 & - \\
\hline & 2001 & $-1.44 \times 10^{-4}$ & 4.28 & -0.20 & 265.3 & 76.9 & - \\
\hline & 2002 & $-1.44 \times 10^{-4}$ & 4.28 & -0.20 & 265.3 & 76.9 & - \\
\hline Total & & & & & & & 693.09 \\
\hline
\end{tabular}

Maximum likelihood values for the ellipsoidal gradient model fitted to the time series data from the southern part of Belgium.

${ }^{a}$ Constant prevalence $(a=0)$ : prevalences $23.7,22.7,27.8,8.6$ and $16.9 \%$ from 1998 to 2002, respectively.

${ }^{b}$ The full model fitted to the data for each separate year can be compared to a model with all parameters shared except the ellipse scale parameter $a$ (bottom block). The deviance (693.09-672.61) can be tested in a likelihood ratio test: the difference in -2 log-likelihood is 20.48 ; this deviance is asymptotically $x^{2}$ distributed with d.f. $=5 \times 5-(5+4)=16$ and $p=0.80$, meaning that the more parsimonious model with shared parameters does not lead to a significant decrease in goodness of fit. 


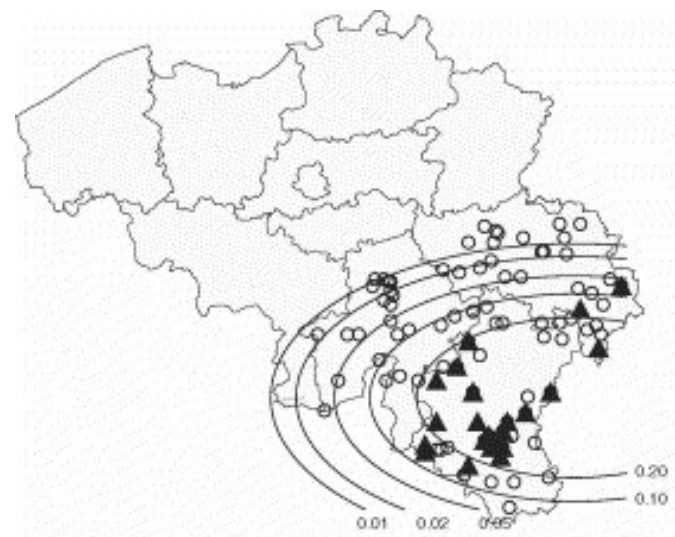

(a) 1998

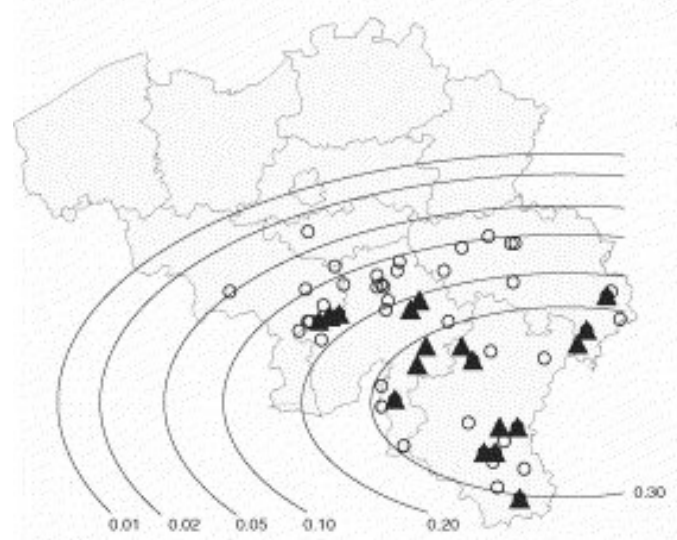

(c) 2000

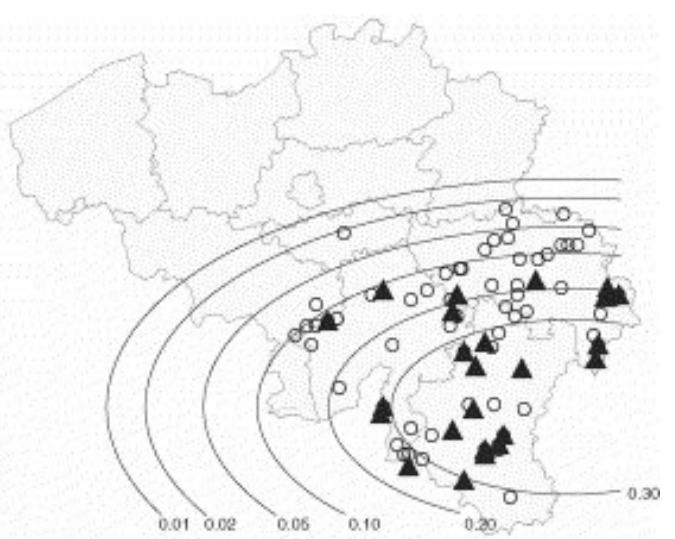

(b) 1999

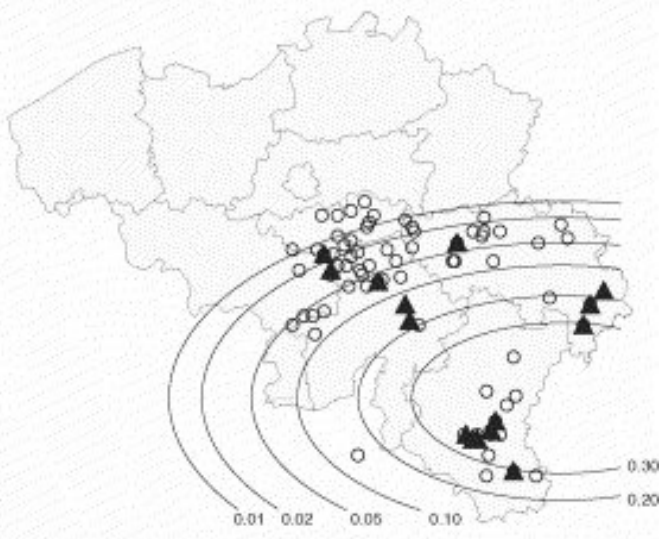

(d) 2001

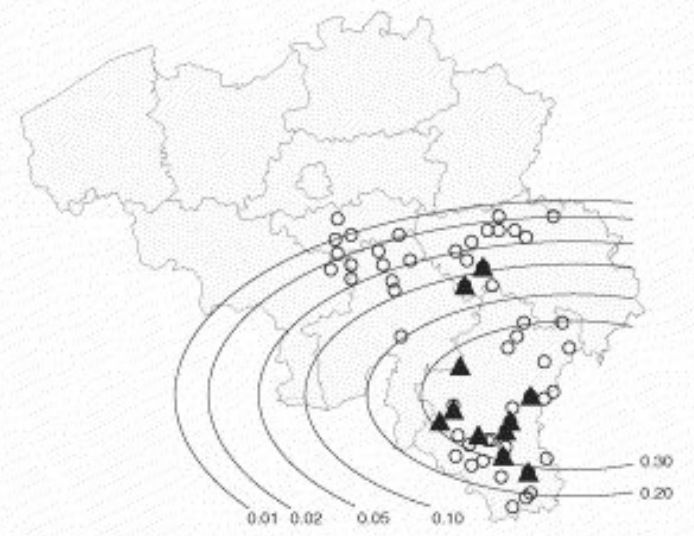

(e) 2002

Fig. 3. Prevalence contours $(\times 100 \%)$ of Echinococcus multilocularis in foxes from Belgium over the period 1998-2002. (+) symbols represent uninfected foxes and (X) symbols represent infected foxes. 


\section{Discussion}

In Belgium and the southern part of The Netherlands, E. multilocularis infection is most frequently found in the southeastern part of Belgium. This was confirmed by a spatial analysis of the distribution patterns. The results indicate that prevalences in northwestern areas are very low $(<1 \%)$ whereas prevalences in southeastern areas may be much higher $(>30 \%)$. Using the same spatial analysis technique, we showed that the fitted gradient is continued across the national border, in a contiguous area in the southern part of the province of Limburg in The Netherlands. To our knowledge this is the first study analysing transnational data to study the spatial distribution of $E$. multilocularis infection across nation borders and we have established a consistent spatial gradient across the complete examined region. Joining data may greatly enhance the potential for spatial analysis because an increased scale allows the detection of spatial patterns which may remain undetected when smaller regions would be considered separately (van der Giessen et al., 2004b).

The spatial analysis used in this paper is different from other methods, like kriging or conditional autoregressive (CAR) models for spatial smoothing (Venables and Ripley, 1994 and Gilks et al., 1996), in that we only consider large-scale variation in prevalence and not local patterns. This makes the gradient method less dependent on data abundance, or uniformity of sampling, though obviously at the expense of spatial resolution. At the margin of the endemic region of the parasite we were mainly interested in the probability that a fox is infected and how this probability changes when we move away from the endemic region. In a low (or non-)endemic country most of the sampled foxes will be uninfected providing little information on the spatial distribution of $E$. multilocularis. A logistic gradient then provides a simple screening method for finding coarse spatial patterns, especially in areas at the margin of the endemic region, to find the direction where the prevalence changes most rapidly. As several of such marginal regions exist in Europe due to the highly heterogeneous spatial distribution of E. multilocularis in foxes (e.g. Giraudoux, 1991 and Tackmann et al., 1998), application of the gradient method may be useful for scientists concentrating on (possibly) newly endemic regions at the margin of established endemic regions. The specific regression equation that is chosen can be easily adapted to the geometry of the studied region. A previous analysis on a smaller scale used a linear model (van der Giessen et al., 2004b). However, in the present study a linear gradient performed poorly (see Table 2A). Hence, in relatively large areas a linear gradient model may become too restrictive and an ellipsoidal gradient model may prove better.

The data of the province of Limburg in The Netherlands appeared to fit well into the spatial pattern of the Belgian infected foxes, although sampling in Limburg province was in 2002-2003, whereas the Belgian data were collected from 1996 to 2002. The spreading pattern found in southern Belgium indicates a tendency for migration into northwestern direction and not in northeastern direction, where the province of Limburg is situated. During the last two decades both the distribution range and population densities of the Red fox increased rapidly in northern Belgium (Vervaeke et al., 2003). In the same period, high prevalences of E. multilocularis were reported in southern Belgium (Brochier et al., 1992, Losson et al., 1997 and Losson et al., 2003). Thus, the overall increase in prevalence of $E$. multilocularis in foxes southwards may indicate that the expanding fox population from southern to northern Belgium (Vervaeke et al., 2003) is accompanied by an increasing infection pressure of E. multilocularis. The parasite may be starting to migrate northwards, as suggested by the low prevalence and patchy distribution of $E$. multilocularis in northern Belgium that is 
likely to be due to a recent range extension of $E$. multilocularis in these areas (Vervaeke et al., 2003). In the province of Limburg in The Netherlands, the prevalence of $E$. multilocularis in foxes decreases in northern direction, also indicating that the parasite might have spread from southern Belgium across the border into areas in the south of The Netherlands (van der Giessen et al., 1999, van der Giessen et al., 2004a and van der Giessen et al., 2004b).

Furthermore, the analysis of annual changes in spatial distribution for a subset of the data from south Belgium revealed an indication of an increase in prevalence as well as a northwestern motion from 1998 to 2000 . This temporal pattern may be consistent with the spread of $E$. multilocularis northwards from southern Belgium. The sudden drop in prevalence in 2001 still remains to be explained. Although the spatial pattern does not seem to change (Table 3 and Fig. 3), the proportion of positive foxes (i.e. 8.6\%) is approximately one-third of that of 2000 (i.e. $27.8 \%$ ). In 2002 , the prevalence is somewhat higher again, still not reaching the level of 1998. Collection and investigation of foxes were not markedly different in 2001 and 2002, compared to the previous years and it seems unlikely that the apparent decrease in prevalence is caused by lower detection rates because the detection method was the same for all studies. The observed differences in prevalence may reflect natural variation due to fluctuations in the fox or rodent populations. If so, a smaller time-scale may provide better information on the changes in spatial spreading.

Interestingly, our results confirm those of van der Giessen et al. (2004b) who studied the spatial distribution of E. multilocularis in the northern part of The Netherlands (province of Groningen). In that study, the prevalence of $E$. multilocularis appeared to change strongest in east-west direction and was highest near the German border, adjacent to a German endemic area. Both this study and ours suggest that the border areas in The Netherlands are the most margin of E. multilocularis territory. The spatial gradient and temporal fluctuations in prevalence of $E$. multilocularis in the Red fox found in this study may support the hypothesis of Tackmann et al. (1998) that the spread of $E$. multilocularis over long distances is due to foxes dispersing from endemic areas.

Finally, an implicit assumption in the modeling of our data is that the population was stable during the period with respect to host characteristics which (i) almost certainly does not reflect the natural situation (for instance, E. multilocularis distribution is patchy in fox populations (Eckert et al., 2001 and Vervaeke, 2004) and (ii) allows the estimation of global prevalence, but not of local prevalence. Hence, we cannot speculate on the effects of, for instance, age structure of the fox population on the increase or decrease of prevalences. Moreover, foxes were collected over unequal (though overlapping) periods and were not collected randomly. Rather, sampling depended on the availability of road-traffic victims and foxes killed by hunters so that foxes may be clustered at places where they tend to die (e.g. main roads), not necessarily where they live. However, any additional local model may be applied in an additive way. For instance, the fixed trend component in a kriging model may be our ellipsoidal gradient. Unfortunately sampling densities differ a great deal between regions, with extremely low numbers of foxes in the northwestern part of Belgium precluding any precise local analysis of spreading patterns. Models employing local spatial structure that correlate prevalence with landscape (e.g. land use) and ecological (e.g. age structure of fox population, susceptablility to E. multilocularis, gender, ...) features will provide invaluable additional information on local prevalences and on the factors that are responsible for the spread of $E$. multilocularis. This will help in the decision-making of whether (and when) or not to implement and to evaluate, preventive measures for E. multilocularis. In this way, our and other models could 
help in the prediction, monitoring and prevention of human $\mathrm{AE}$.

\section{Acknowledgements}

Thanks to a grant from F.W.O. Vlaanderen to Muriel Vervaeke which made this research possible. The study in Limburg (The Netherlands) was financed by the Inspectorate of Health Protection and Veterinary Public Health and EU project QLK2-CT-2001-01995: Echinorisk.

\section{References}

Ammann and Eckert, 1995 R. Ammann and J. Eckert, Clinical diagnosis and treatment of Echinococcosis in humans. In: R.C.A. Thompson and A.J. Lymbery, Editors, Echinococcus and Hydatid Disease, C.A.B. International, Wallingford (1995), pp. 411-463.

Artois, 1997 M. Artois, Managing problem wildlife in the 'Old world': a veterinary perspective, Reprod. Fertil. Dev. 9 (1997), pp. 17-25.

Balicka-Ramisz et al., 2003 A. Balicka-Ramisz, A. Ramisz, B. Pilarczyk and R. Bienko, Fauna of gastrointestinal parasites in red foxes in Western Poland, Med. Wet. 59 (2003), pp. 922-925.

Brochier et al., 1992 B. Brochier, P. Coppens, B. Losson, M.F.A. Aubert, B. Bauduin, M.J. Barrat, F. Costy, D. Peharpre, L. Pouplard and P.P. Pastoret, Enquête sur l'infestation du Renard roux (Vulpes vulpes) par Echinococcus multilocularis en province de Luxembourg (Belgique), Ann. Méd. Vét. 136 (1992), pp. 497-501.

Carlin and Louis, 1996 B.P. Carlin and T.A. Louis, Bayes and Empirical Bayes Methods for Data Analysis, Chapman and Hall, London (1996).

Delplazes and Eckert, 1996 P. Delplazes and J. Eckert, Diagnosis of the Echinococcus multilocularis infection in final hosts, Appl. Parasitol. 37 (1996), pp. 245-252.

Deplazes and Eckert, 2001 P. Deplazes and J. Eckert, Veterinary aspects of alveolar echinococcosis, a zoonosis of public health significance, Vet. Parasitol. 98 (2001), pp. 65-87.

Deplazes et al., 2004 P. Deplazes, D. Hegglin, S. Gloor and T. Romig, Wilderness in the city: the urbanisation of Echinococcus multilocularis, Trends Parasitol. 20 (2004), pp. 77-84.

Dubinsky et al., 1999 P. Dubinsky, V. Svobodova, L. Turcekova, K. Litterak, K. Martinek, K. Reiterova, L. Kolarova, J. Klimes and V. Mrlik, Echinococcus multilocularis in Slovak Republic: the first record in red foxes, Helminthologia 36 (1999), pp. 105-110.

Eckert and Deplazes, 1999 J. Eckert and P. Deplazes, Alveolar echinococcosis in humans: the current situation in Europe and the need for countermeasures, Parasitol. Today 15 (1999), pp. 315-319.

Eckert et al., 2000 J. Eckert, F.J. Conraths and K. Tackmann, Echinococcosis: an emerging or reemerging zoonosis?, Int. J. Parasitol. 30 (2000), pp. 1283-1294.

Eckert et al., 2001 In: J. Eckert, M.A. Gemmell, F.-X. Meslin and Z.S. Pawlowski, Editors, WHO/OIE Manual on Echinococcosis in Humans and Animals: A Public Health Problem of Global Concern, OIE, France (2001), p. 265.

Eskens, 1997 von U. Eskens, Zum vorkommen von Echinococcus multilocularis bei Rotfüchsen im Einzugsgebiet des Staatslichen Medizinal- Lebensmittel- und Veterinäruntersuchungsamts Mittelhessen, Z. Jagdwiss. 43 (1997), pp. 154-165.

Gilks et al., 1996 W.R. Gilks, S. Richardson and D.J. Spiegelhalter, Markov chain Monte Carlo in Practice, Chapman and Hall, London (1996). 
Giraudoux, 1991 Giraudoux, P., 1991. Utilisation de I'espace par les hôtes du ténia multiloculaire (Echinococcus multilocularis): conséquences épidémiologiques. Ph.D. Thesis. University of Dijon, France.

Giraudoux et al., 2001 P. Giraudoux, F. Raoul, K. Bardonnet, P. Vuillaume, F. Tourneux, F. Cliquet, P. Delattre and D.A. Vuitton, Alveolar echinococcosis: characteristics of a possible emergence and new perspectives in epidemiosurveillance, Méd. Mal. Infect. 31 (2001), pp. 247-256.

Gloor et al., 2001 S. Gloor, F. Bontadina, D. Hegglin, P. Deplazes and U. Breitenmoser, The rise of urban fox populations in Switzerland, Mamm. Biol. 66 (2001), pp. 155-164.

Hofer et al., 2000 S. Hofer, S. Gloor, U. Müller, A. Mathis, D. Hegglin and P. Deplazes, High prevalence of Echinococcus multilocularis in urban red foxes (Vulpes vulpes) and voles (Arvicola terrestris) in the city of Zürich Switzerland, Parasitology 120 (2000), pp. 135-142.

Kern et al., 2003 P. Kern, K. Bardonnet, E. Renner, H. Auer, Z. Pawlowski, R.W. Ammann, D.A. Vuitton and P. Kern, European echinococcosis registry: human alveolar echinococcosis, Europe 19822000, Emerg. Infect. Dis. 9 (2003), pp. 343-349.

Kolarova et al., 1996 L. Kolarova, I. Pavlasek and J. Chalupsky, Echinococcus multilocularis (Leuckart 1863 ) in the Czech Republic, Helminthologia 33 (1996), pp. 59-65.

Kolarova, 1999 L. Kolarova, Echinococcus multilocularis: new epidemiological insights in Central and Eastern Europe, Helminthologia 36 (1999), pp. 193-200.

Losson et al., 1997 B. Losson, B. Mignon, B. Brochier, B. Bauduin and P.P. Pastoret, Infestation du Renard roux (Vulpes vulpes) par Echinococcus multilocularis dans la Province de Luxembourg (Belgique): résultats de l'enquête effectuée entre 1993 et 1995, Ann. Méd. Vét. 141 (1997), pp. 149153.

Losson et al., 2003 B. Losson, T. Kervyn, J. Detry, P.-P. Pastoret, B. Mignon and B. Brochier, Prevalence of Echinococcus multilocularis in the red fox (Vulpes vulpes) in southern Belgium, Vet. Parasitol. 117 (2003), pp. 23-28.

Lucius and Bilger, 1995 R. Lucius and B. Bilger, Echinococcus multilocularis in Germany: increased awareness or spreading of a parasite?, Parasitol. Today 11 (1995), pp. 430-434.

Rausch, 1995 R. Rausch, Life cycle patterns and geographic distribution of Echinococcus species. In: R.C.A. Thompson and A.J. Lymbery, Editors, Echinococcus and Hydatid Disease, C.A.B. International, Wallingford (1995), pp. 89-134

Romig et al., 1999 T. Romig, B. Bilger, A. Dinkel, M. Merli and U. Mackenstedt, Echinococcus multilocularis in animal hosts: new data from Western Europe, Helminthologia 36 (1999), pp. 185191.

Romig, 2002 T. Romig, Spread of Echinococcus multilocularis in Europe?. In: P. Craig and Z. Pawlowski, Editors, Cestode zoonoses: Echinococcosis and Cysticercosis, IOS Press, Amsterdam (2002), pp. 65-80

Schantz et al., 1995 P.M. Schantz, J. Chai, P.S. Craig, J. Eckert, D.J. Jenkins, C.N.L. Macpherson and A. Thakur, Epidemiology and control of Hydatid Disease. In: R.C.A. Thompson and A.J. Lymbery, Editors, Echinococcus and Hydatid Disease, C.A.B. International, Wallingford (1995), pp. 233-331.

Sréter et al., 2003 T. Sréter, Z. Szell, Z. Egyed and I. Varga, Echinococcus multilocularis: an emerging pathogen in Hungary and Central Eastern Europe?, Emerg. Infect. Dis. 9 (2003), pp. 384-386.

Tackmann et al., 1998 K. Tackmann, U. Löschner, H. Mix, C. Staubach, H.-H. Thulke and F.J. Conraths, Spatial distribution patterns of Echinococcus multilocularis (Leuckart, 1863) (Cestoda: Cyclophyllidea: Taeniidae) among red foxes in an endemic focus in Brandenburg, Germany, Epidemiol. Infect. 120 (1998), pp. 101-109.

van der Giessen et al., 1999 J.W.B. van der Giessen, Y.B. Rombout, J.H. Franchimont, L.P. Limper and W.L. Homan, Detection of Echinococcus multilocularis in foxes in The Netherlands, Vet. Parasitol. 82 (1999), pp. 49-57. 
Preventive Veterinary Medicine Volume 76, Issues 3-4, 17 October 2006, Pages 137-150

van der Giessen et al., 2004a van der Giessen, J.W.B., De Vries, A., Chu, M.L., Stortelder, V., Mulder, J.L., de Lezenne Coulander, C., Teunis., P., 2004a. The prevalence of $E$. multilocularis in foxes in Limburg, 2002-2003. RIVM Report 330040001.

van der Giessen et al., 2004b J.W.B. van der Giessen, Y. Rombout and P. Teunis, Base line prevalence and spatial distribution of Echinococcus multilocularis in a newly recognized area in The Netherlands, Vet. Parasitol. 119 (2004), pp. 27-35.

Venables and Ripley, 1994 W.N. Venables and B.D. Ripley, Modern Applied Statistics with S-plus, Springer Verlag, Berlin (1994).

Vervaeke et al., 2003 M. Vervaeke, K. Van Den Berge, F. Vercammen, S. Geerts, J. Brandt, P. Dorny and R. Verhagen, Echinococcus multilocularis (Cestoda Taeniidae) in Red foxes (Vulpes vulpes) in northern Belgium, Vet. Parasitol. 115 (2003), pp. 257-263.

Vervaeke, 2004 Vervaeke, M., 2004. Zoonotic infections of the Red fox (Vulpes vulpes) in EuropeImplications for wildlife management. Ph.D. Dissertation. Universiteit Antwerpen, Belgium.

Vervaeke et al., 2005 M. Vervaeke, P. Dorny, L. De Bruyn, F. Vercammen, K. Jordaens, K. Van Den Berge and R. Verhagen, A survey of intestinal helminths of red foxes (Vulpes vulpes) in northern Belgium, Acta Parasitol. 50 (2005), pp. 221-227. 